\title{
LA TENDENCIA A LA DESPRESENCIALIZACION DE LA EDUCACIÓN SUPERIOR EN AMÉRICA LATINA
}

\author{
(THE TREND TOWARDS DESPRESENCIALIZACION OF \\ HIGHER EDUCATION IN LATIN AMERICA)
}

\author{
Claudio Rama Vitale \\ Virtual Educa (Uruguay)
}

\section{RESUMEN}

El presente artículo analiza como se ha ido articulando el proceso de desarrollo de la educación virtual en el sector de la educación superior en América Latina avanzando hacia la focalización del impacto de las nuevas tecnologías en las modalidades de la educación a distancia y a como ellas están contribuyendo a un nuevo proceso de diferenciación tanto de la educación en general como de la educación a distancia en particular que asume una multimodalidad. El artículo visualiza las tipologías institucionales de las manifestaciones de lo que define como un proceso de despresencialización de la educación superior, e identifica una propuesta de las características más dominantes de esas tendencias de la expansión de la educación a distancia en la región.

Palabras clave: educación virtual, tendencias, universidades, América Latina, presencialidad, educación superior.

\begin{abstract}
This article analyse the process of development of virtual education in the higher education sector in Latin America moving toward a focus on the impact of new technologies on the modalities of distance education and how they are contributing a new process of differentiation of both general education and distance education in particular assuming a multimodality. The article displays the types of institutional manifestations of what is defined as a process despresencializacion of higher education, and identifies a proposal of the most dominant of these trends is the expansion of distance education in the region.
\end{abstract}

Keywords: virtual education, trends, universities, Latin America, higher education. 


\section{EL MODELO TRADICIONAL DE EDUCACIÓN A DISTANCIA INFORMAL EN AL}

La educación a distancia ha tenido una larga y profusa experiencia en muchos países y regiones del mundo (García Aretio, 1999). A diferencia en América Latina, la educación a distancia ha tenido una reciente y relativa presencia histórica y focalizada en la educación no formal. Su desarrollo se produjo desde los años 50 y ha estado asociado a la formación docente, a programas de alfabetización para adultos y a la educación intercultural bilingüe para indígenas. Los maestros en ejercicio, la población adulta analfabeta y la población indígena fueron los primeros receptores de esta modalidad educativa en el continente, generada en organismos burocráticos públicos creados para tal fin o a través de programas específicos. Más allá de su amplia diferenciación en regiones y países, en general esta educación a distancia no estaba articulada al interior de las instituciones educativas dentro del sector formal, sino que era en general resultado de proyectos puntuales que buscaban cubrir una demanda específica insatisfecha que no lograba responder el sector formal. Era concebida como una educación remedial o compensatoria de la enseñanza.

La educación a distancia orientada a los docentes en ejercicio, propendía a la actualización de sus competencias así como el desarrollo de un mecanismo que permitiera también la certificación de competencias a partir de determinados módulos de enseñanza y la realización de pruebas asociadas a estos cursos a distancia. La dispersión geográfica de los docentes en las escuelas, las carencias financieras para el traslado a los centros de educación tradicional (las normales), el corresponder a un momento histórico signado por el fuerte crecimiento de la cobertura media y básica, el ser una población adulta, y ser estos cursos obligatorios o asociados a ingresos salariales adicionales, fueron los ejes que facilitaron e incentivaron que la formación docente en varios lugares utilizara la educación a distancia. Los países de desarrollo educativo tardío fueron el ejemplo. México fue un caso muy significativo de este proceso, asociado además a nuevas concepciones sobre el rol del maestro en las comunidades y de la búsqueda de aumentar la calidad en contextos de creciente expansión de las demandas de acceso en poblaciones rurales a través de la profesionalización de los docentes.

Igualmente, en el caso de la población indígena, un instrumento importante de educación fue la modalidad a distancia. Su alta dispersión en los territorios, la dificultad de desarrollar procesos formales de enseñanza conjuntas para la población indígena y no indígena, dadas sus especiales necesidades educativas por sus carencias lingüísticas y el tipo de pertinencia y de mercado laboral específico en las comunidades, 
facilitaron el uso de las metodologías de la educación a distancia para esos sectores. Finalmente, las políticas de alfabetización y de educación de adultos, también por su dispersión, por su carácter de ser programas puntuales que permitiesen leer y escribir a esta población y facilitar algunos recorridos en el sector formal, llevaron al uso intensivo de modalidades de educación a distancia para estos sectores. El cuadernillo, los programas radiales, o inclusive la televisión, fueron los instrumentos didácticos que apoyaron esas modalidades educativas en varios países.

Así, la educación a distancia nace en el continente asociada a espacios informales de enseñanza, destinada a públicos específicos y dispersos, a través de modalidades organizacionales, en general no permanentes, bajo la supervisión de los Ministerios de Educación, y siempre pensadas como aprendizajes remediales de compensación para permitir alcanzar los conocimientos que el sector formal no había logrado transmitir a estas personas. Eran también educaciones terminales, y no estaban en general articuladas con otros sectores o niveles que pudieran permitir recorridos académicos posteriores para estos sectores.

Podría decirse que era una educación marginal a las estructuras formales para formar a sectores excluidos de estos niveles, y los cuales carecían en general de las continuidades, los procesos de supervisión y de evaluación académica, las articulaciones académicas, y los niveles de calidad de las modalidades presenciales. Nació como educación de baja calidad para llevar adelante procesos educativos remediales para sectores con bajos capitales culturales, y contribuyó por ende a conformar un núcleo de opinión crítico y negativo sobre el valor de esta modalidad educativa.

\section{EL INGRESO DE LA EDUCACIÓN A DISTANCIA EN LA EDUCACIÓN SUPERIOR}

En los setenta en la región y a escala mundial, se produjo un cambio significativo en la educación a distancia, al conformarse ésta como un instrumento educativo también para el nivel superior. Si bien ya existían experiencias, fundamentalmente en Estados Unidos al interior de las Universidades, es con el nacimiento de la Open University en Inglaterra y posteriormente de la Universidad Nacional de Educación a Distancia (UNED) de España, cuando la educación a distancia se comienza a consolidar como una de las modalidades de la educación superior, con sus propias características y especificidades. En América Latina, tal influencia, tuvo su correlato en la existencia de crecientes demandas de acceso a la educación superior por parte 
de nuevos sectores sociales, de una mayor complejización de la educación presencial y de la existencia de restricciones financieras para continuar expandiendo la cobertura a través de las mismas modalidades existentes.

En la región, la expansión de las mayores demandas de acceso derivó en el mantenimiento de la gratuidad y en la introducción de sistemas selectivos de ingreso a las universidades públicas. Tales decisiones plantearon el inicio de la diferenciación de la educación superior, cuyos ejes más marcados estuvieron dados por la propia diferenciación del sector público a través de nuevas instituciones con menos autonomía, recursos y complejidades académicas; la expansión de la nueva dinámica de la educación privada marcada por su carácter de absorción de demanda; el desarrollo de una educación terciaria no universitaria para sectores de menores ingresos; y también por el nacimiento de la educación superior a distancia.

En una amplia variedad de países de la región, y a través de diversas formas institucionales, se produjo el nacimiento de la educación a distancia en la educación superior, en el marco de un modelo conceptual similar en toda la región. La educación superior a distancia que se gestó asumió la forma de una educación semipresencial con el apoyo de materiales didácticos escritos, la existencia de tutores con una atención a través de sedes distribuidas en el país y en las cuales además se realizan las evaluaciones de los aprendizajes, ya que los exámenes eran presenciales. Bajo este modelo educativo, el acceso era libre y no requería de pruebas selectivas como en las universidades presenciales. El público objetivo por su parte además de aquellos excluidos del acceso público, era de adultos y se focalizó en sectores de menos ingresos económicos y de menores capitales culturales que no lograban acceder al modelo de tipo dual, por un lado, un sector público con examen de ingreso, y por el otro, privado con matrícula arancelada.

En muchos países de la región la diferenciación institucional y las demandas de acceso a la educación se expresaron en una de sus orientaciones a través de esta modalidad de enseñanza, lo cual dio inicio a la bimodalidad educativa en la región. Este ingreso de la bimodalidad, sin embargo se produjo a través de una alta diversidad de expresiones, en función de las particularidades propias de cada país.

Una de las expresiones de esta nueva realidad, y sin duda la más conocida, consistió en la creación de nuevas universidades preferentemente públicas, orientadas a ofertar bajo estas modalidades pedagógicas a distancia bajo modelos educativos semipresenciales. Ella fue la primera oleada de las instituciones de educación a distancia. Las expresiones más importantes fueron la Universidad Estatal a Distancia 
(UNED) de Costa Rica, la Universidad Nacional Abierta (UNA) de Venezuela y la Universidad Nacional Abierta y a Distancia (UNAD) de Colombia. En estos países, estas instituciones estuvieron asociadas al establecimiento de exámenes de ingreso altamente selectivos en las Universidades y funcionaron como ofertas de estudios terciarios sin restricciones de ingreso. Mientras que las universidades públicas introducían restricciones al acceso, se creaban en paralelo oportunidades de ingreso abierto a menos costos por alumno y preferentemente para la población adulta. Tal desarrollo se asoció al modelo de la Open University que se basaba en la ausencia de restricciones de ingreso y la existencia de restricciones de egreso, a partir de altos estándares de calidad del proceso de aprendizaje. En el sector privado, la expresión más clara de esta modalidad en ese momento se dio con la Universidad Técnica Particular de Loja en Ecuador.

En la región estas modalidades de ofertas de educación a distancia nacieron además con menos niveles de autonomía, más dependientes de los Ministerios de Educación, y con presupuestos por alumnos significativamente inferiores que las restantes instituciones públicas. En Venezuela la UNA para el 2004 tiene un costo por alumno de 1.14 millones de bolívares, mientras que la universidad más costosa, la Simón Bolívar, tiene un costo por alumno de 12,89 millones de bolívares y una media nacional del sector público de 5,39 millones de bolívares. En el caso de Colombia, el costo por alumno de la UNAD para el 2006 fue de 0,626 millones de pesos, mientras que la Universidad más costosa, la Universidad Nacional tuvo un costo por alumno de 11,494 millones de pesos, y la media nacional del costo por alumno en la educación superior pública fue 5,007 millones de pesos. Mientras que en Venezuela la diferencia entre la más cara y la UNA es 11,30 veces en Colombia, la diferencia es mayor y alcanzó a 21,12 veces. ${ }^{1}$ Tales diferencias también se han expresado en menores niveles de calidad, de formación de sus docentes y también de infraestructuras muy inferiores a las de las restantes instituciones públicas. También de menos autonomía, lo cual ha marcado que el recorrido político de estas tres Universidades ha sido también el de la lucha por la obtención de la autonomía, que la UNED obtuvo a los cinco años de su creación, la UNAD en el 2005, y que la UNA carece al estar regida por la Ley de Universidades de 1971 que establece una menor autonomía para las universidades experimentales.

Las nuevas demandas por el acceso a la educación superior no presencial se expresaron tanto a través de estas nuevas instituciones orientadas a la oferta de modalidades educativas a distancia, como lentamente también con la expansión de ofertas a distancia dentro de instituciones presenciales. Mientras que en el primer caso se desarrollaron instituciones tanto privadas, como fundamentalmente públicas 
que nacieron con la exclusiva misión de desarrollar ofertas bajo la modalidad a distancia, y en el segundo caso, la expansión de la educación a distancia, se expresó en la conformación de modelos bimodales de educación superior al interior de las instituciones que en diversa proporción utilizaban y mezclaban ofertas presenciales y ofertas a distancia. Los casos más llamativos de bimodalidad pública en la región se dieron en México y Honduras, donde se desarrollaron ofertas de educación a distancia al interior de las Universidades autónomas, que comenzaron a estructurar un modelo bimodal en términos pedagógico, organizativo y tecnológico. Casi todas las grandes Universidades autónomas de México, como la UNAM, la Universidad de Guadalajara, la de Veracruz o la de Puebla, comenzaron a ofertar, en el marco de sus políticas de regionalización y de restricciones de acceso abierto, una nueva oferta educativa a través de la educación a distancia, bajo dinámicas semipresenciales con apoyo del libro y de guías didácticas especiales. La UNAM, como en muchos otros temas, abrió un camino en la región, al establecer en forma autónoma, al tiempo que la prueba selectiva de acceso bajo la gratuidad, una oferta educativa semipresencial sobre la base de propender a ofrecer los mismos niveles y estándares de calidad que la educación presencial universitaria. En 1974 se crea el Sistema de Universidad Abierta (SUA) de la UNAM que propendía a ofrecer oportunidades de acceso a la institución, dado el establecimiento de cupos y exámenes a la educación presencial, para aquellos que no lograban ingresar. El modelo del SUA posteriormente también se basó en una selectividad de acceso, pero con menor presión de postulantes versus ingresantes. La Universidad Central de Venezuela (UCV) también desde la década del 70, asociado al establecimiento de restricciones de acceso, propendió, aunque en muy reducida proporción, a desarrollar modalidades de educación a distancia para quienes no podían acceder a los sistemas presenciales.

A diferencia otro modelo de expansión de la educación a distancia al interior de las universidades públicas se dio, en Honduras, tanto en la Universidad Nacional Autónoma de Honduras (UNAH) desde 1985, como posteriormente en la Universidad Nacional Pedagógica (UNPFM). En estas instituciones se desarrolló un modelo bimodal con una educación presencial por una parte y por la otra, una educación superior a distancia (semipresencial), y cuyas diferencias, en teoría eran sólo de metodología de enseñanza y no por la forma del acceso, ya que se carecía de selectividad de acceso a la educación presencial. En este caso, la educación a distancia, se viabilizaba fundamentalmente para cubrir demandas en parte del territorio nacional en el cual no había sedes regionales de ambas instituciones que ofertaran educación superior en forma presencial. Ambos modelos con el tiempo, aún siendo de acceso libres y sin sistemas de evaluación, se tendieron a diferenciar en la calidad, el tipo de estudiante y el tipo de oferta disciplinaria. 
En otras universidades autónomas también se desarrollaron modalidades bimodales pero asociadas a las propias Facultades y Escuelas, y no como una modalidad educativa distinta a nivel de toda la institución sino a nivel de las unidades académicas de base, de las carreras o materias. Ellas se asociaron al nombre de "estudios libres" y tuvo sus ejemplos en la Universidad de Buenos Aires (así como varias de las grandes públicas de Argentina) y en la Universidad de la República en el Uruguay (UDELAR), que en el marco de modelos de acceso abiertos y dada la saturación de las aulas y las limitaciones físicas de espacio, propendieron a establecer restricciones de acceso al establecer modalidades de educación a distancia de tipo semipresencial, donde algunos estudiantes estaban autorizados u obligados a llevar algunas materias en forma semipresencial y sólo estaban obligados a rendir en forma presencial los exámenes finales junto a aquellos que seguían el curso en forma regular. En estos casos, el carácter fragmentado de las universidades públicas con fuerte peso de las Facultades llevó al desarrollo de estas modalidades de oferta a distancia y a formas bimodales, no a nivel central, sino independientemente por parte de las distintas Facultades en función de sus diferenciadas presiones de cobertura y de problemas locativos.

\begin{tabular}{|c|c|c|}
\hline Sistémicas & $\begin{array}{c}\text { Creación de instituciones dedicadas a } \\
\text { ofertar exclusivamente bajo la modalidad } \\
\text { de educación a distancia }\end{array}$ & $\begin{array}{c}\text { Venezuela (UNA), Costa Rica } \\
\text { (UNED), Colombia (UNAD), } \\
\text { Ecuador, (UTPL), México } \\
\text { (TEC) }\end{array}$ \\
\hline Intrauniversitarias & $\begin{array}{c}\text { Creación de unidades de la Universidad a } \\
\text { nivel central dedicadas exclusivamente a } \\
\text { ofertar educación a distancia }\end{array}$ & $\begin{array}{c}\text { México (UNAM, UDG, } \\
\text { Veracruz), Honduras (UNAH, } \\
\text { UNPFM) }\end{array}$ \\
\hline Interfacultades & $\begin{array}{c}\text { Separación de estudios regulares y de } \\
\text { estudios libres a nivel de las carreras, y } \\
\text { desarrollo de modalidades de educación } \\
\text { a distancia a nivel de la Facultad o } \\
\text { Carrera }\end{array}$ & $\begin{array}{c}\text { Uruguay (UDELAR), Argentina } \\
\text { (UBA, U de Córdoba, U de la } \\
\text { Plata) }\end{array}$ \\
\hline
\end{tabular}

Cuadro 1. Formas Bimodales de la Educación Superior a Distancia Semipresencial

En general (salvo la excepción de Honduras) la educación superior a distancia durante esta fase se estructuró bajo distintos sistemas bimodales, articulados entre una selección de acceso por un lado, y accesos abiertos para un público de bajo capital cultural y de bajos ingresos económicos, por el otro. Ello marcó en general el carácter gratuito y público de la educación superior a distancia, y su propio rol como una modalidad educativa de menor costo durante esta fase. Sin embargo, también se desarrollaron en la región en esta fase, algunas manifestaciones de ofertas de educación a distancia por parte de instituciones privadas. Entre esos casos cabe 
destacar la Universidad Técnica Particular de Loja en Ecuador y el Tecnológico de Monterrey en México, las cuales en sus inicios desarrollaron también un modelo educativo semipresencial y se expandieron en sus respectivos países que carecían de amplios sistemas de acceso públicos a distancia. Ambos siguieron orientaciones inversas. El Tecnológico de Monterrey, institución sin fines de lucro nacida en el año 1943 y muy vinculado a sectores empresariales de México, se focalizó en estudiantes de altos ingresos y un modelo educativo a escala regional basado en la tercera generación de la educación a distancia (videoconferencias). Tal modelo fracasó fundamentalmente por cuanto las familias no estaban dispuestas a pagar altos costos por una educación que era a distancia y de inferior calidad. El Tec produjo un cambio radical y se reorientó a un modelo presencial de elites con alta incorporación de tecnologías de comunicación e información. Recién posteriormente con la aparición de las tecnologías digitales avanzó hacia la creación de un modelo de educación superior a distancia virtual, que asumió el nombre de Tec Virtual para sectores de menos ingresos y sobre la base de apoyos financieros del sector público.

Por su parte, la otra iniciativa privada significativa, la Universidad Técnica Particular de Loja, en Ecuador, desarrolló un modelo tradicional de educación superior a distancia semipresencial con apoyo en sedes y focalizado en sectores de menores ingresos, de difícil accesibilidad a la educación presencial y con bajos costos de la matrícula. En este caso la viabilidad económica estuvo dada por su gran escala, los bajos costos salariales del interior del país, el carácter no lucrativo religioso de la institución, una eficiente gestión y controles de calidad, así como bajo un apoyo público en un contexto donde algunas universidades privadas están cofinanciadas por el Estado.

Desde la década del 8o, la educación superior a distancia se fue expandiendo lentamente en toda la región, aún a pesar de las múltiples restricciones políticas, académicas y en algunos casos inclusive normativas. La expansión de esta modalidad educativa en general se dio sobre la base de ausencia de políticas públicas, y más aún, de un cierto ocultamiento de esta realidad educativa. Salvo los casos de la UNED, la UNAD y la UNA que siempre tuvieron una mayor visibilidad y se constituyeron como modelos de política pública por ser universidades, el resto de las ofertas públicas no estaban claramente develadas en las estadísticas, permitiendo así un cierto ocultamiento de una realidad en lento pero persistente crecimiento. La expansión de este modelo pedagógico a distancia, carente de tecnologías interactivas y que asumió la forma de educación semipresencial abierta se dio también con el ingreso hacia fines de los 90 de nuevos proveedores locales privados como fueron por ejemplo la Universidad del Caribe (UC) y la Universidad Abierta para Adultos (UAPA) en 
República Dominicana, o la Universidad de Salta y la Universidad Blas Pascal en Argentina, o la Universidad de Los Ángeles de Chimbote en Perú que ingresaron con los mismos modelo de educación a distancia semipresencial abierta.

\section{EL IMPACTO DE LAS NUEVAS TECNOLOGÍAS}

Una nueva fase de la educación a distancia se abrió a escala general y también en América Latina con la irrupción de las nuevas tecnologías digitales de comunicación e información desde fines de la década del noventa (Aretio, 2007). Ellas han planteado el inicio de una nueva generación de la educación a distancia y también la posible transformación del modelo educativo que ha primado en la región, que se ha basado en el uso del libro y otros materiales instruccionales impresos como determinantes de los procesos de enseñanza-aprendizaje (primera generación). A diferencia, el uso de la televisión y de la radio que corresponden a la segunda generación de la educación a distancia, no fueron utilizadas en la educación superior a distancia, salvo con la excepción del Tecnológico de Monterrey. La aparición del nuevo escenario ha planteado la posibilidad del desarrollo de una nueva generación de la educación superior a distancia, pero sobre todo viabiliza el pasaje desde el uso de un instrumento exclusivo de comunicación a una amplia paleta de utilización de las diversas tecnologías, de un modelo puro de educación a distancia a un modelo híbrido, que combina elementos abiertos (libros), analógicos (medios hertzianos), digitales (Internet), sobre la base de la convergencia digital.

El escenario tecnológico está impulsando que todas las instituciones que brindaban ofertas de educación, y entre ellas también las de a distancia, estén abocadas en los últimos años a un proceso de transformación derivado de la incorporación de las tecnologías derivadas de la revolución de la microelectrónica. Es una transición, que en algunos casos de la educación a distancia, asume formas de reingenierías organizacionales, dadas por el pasaje desde tecnologías analógicas a tecnologías digitales, desde modalidades de comunicación unívocas hacia modalidades de comunicación biunívocas, desde soportes hertzianos con baja segmentación, alta cobertura pero que estaban acotadas a las fronteras nacionales dadas las características de las autorizaciones de potencia y altura de torre de los medios de comunicación hacia mecanismos, y modalidades de comunicación a través de las redes digitales que no carecen de límites geográficos de cobertura, y que por ende, en este caso, tales reingenierías pueden incluir dinámicas internacionales. Desde materiales instruccionales planos hacia procesos de aprendizaje en red que permiten el hipertexto como mecanismo de aprendizaje y de los modelos de 
simulación digitales que se articulan a las concepciones más modernas sobre la experimentación como mecanismos de aprendizajes más eficientes.

La irrupción de las tecnologías de comunicación e información desde los noventa han planteado tanto la realización de transformaciones en las instituciones que tenían ofertas a distancia como también un incentivo al ingreso de nuevos proveedores, tanto locales como internacionales en el campo de la educación superior a distancia. En el caso de las tradicionales universidades a distancia se plantea su posible transformación desde instituciones de educación a distancia basadas en el uso de las tecnologías de la primera y de la segunda generación hacia instituciones basadas en tecnologías de tercera generación y que, por la convergencia, pueden integrar a las modalidades tecnológicas anteriores en sus propias plataformas digitales. Ello bien sea a través de formas puras o híbridas dadas por las diversas combinaciones posibles de tecnologías de comunicación (presencial, libro, televisión, etc.) en el proceso de enseñanza (Bates, 2001).

Las tecnologías digitales están viabilizado el inicio en las universidades aunque con distinta intensidad, de una reingeniería de proceso, de producto y organizacional, que está tendiendo a la virtualización de la enseñanza. El nuevo escenario es tanto con una tecnología exclusiva como también con una amplia paleta de utilización tanto de las viejas como de las nuevas tecnologías, ya que se abren nuevas modalidades de ofertas al interior de la educación a distancia, complejizando la propia bimodalidad, ya no sólo puede presencial versus semipresencial abierta, sino también de una educación a distancia abierta versus una educación digital.

La transformación de las ofertas de educación a distancia desde la utilización de unas modalidades tecnológicas como el libro y el tutor presencial, hacia otras, como aquellas que se basan en modelos de autoaprendizaje acompañados por tutorías virtuales en entornos colectivos (o aulas virtuales) encuentra su fundamentación en el incremento de la flexibilidad, en el aumento de la cobertura y en la disminución de los costos por alumno que el nuevo modelo significa. El eje de la incorporación de productos e industrias culturales (libro, disco, video, Internet o software) está asociado a los beneficios que ellos permiten introducir en los procesos de enseñanza - aprendizaje. En este sentido, las reingenierías que se introducen, no son reformas dentro de un mismo paradigma, sino transiciones hacia nuevos modelos educativos que implicarán complejas reingenierías en la organización para viabilizar el desarrollo de nuevos procesos y productos educativos, así como nuevos soportes de los contenidos. Las reformas derivadas de esas reingenierías se asocian a búsqueda de mejorías en la calidad, en la cobertura y en los costos a partir de la digitalización 
del proceso tecnológico. Además, encontramos múltiples interconexiones: menores costos para los usuarios, recursos didácticos más fieles a la realidad, miniaturización de dichos recursos, mayor interactividad, etc., que refuerzan las líneas anteriores de costos, calidad y cobertura.

- La calidad se incrementa dada la mayor capacidad de interacción en tiempo real de los procesos de enseñanza, por la capacidad de utilizar en el marco de la convergencia tecnológica una mayor cantidad de materiales instruccionales (videos, láminas de power point, imágenes planas, audio), por la posibilidad de acceder a materiales interactivos, por la posibilidad de aprendizajes sincrónicos que permiten niveles de interacciones en tiempo real y una mayor posibilidad de acceder a procesos de aprendizaje con un mayor peso de paradigmas constructivistas, y una mayor capacidad de poder formular preguntas y respuestas inmediatas. La calidad, derivada de la confluencia de medios visuales, auditivos y escritos, así como la interacción y la experimentación, aumentan la retención y la comprensión de los temas.

- La cobertura por su parte se puede incrementar significativamente, al incorporarse otros sectores sociales dotados de mayor conectividad y capacidad de absorber esos costos y los de los equipamientos, así como estudiantes localizados en el extranjero dado el acceso en red o con movilidad reducida como las personas con discapacidades o privadas de libertad. Pero fundamentalmente en términos de cobertura la incorporación de tecnologías digitales permite segmentaciones a escalas muy reducidas, que significa una mejoría respecto a los medios hertzianos que tienen escalas muy elevadas y se orientan a producciones de masas homogéneas.

- Los costos finalmente se articulan en una ecuación de costos - calidad cobertura distinta a la educación presencial y semipresencial, donde el costo por alumno es menor, dada la caída de los costos de los envases de casetes y libros, así como de sedes y aulas para realizar las asistencias y tutorías, y la transferencia de parte de los costos de conexión y de los equipamientos a los estudiantes. Igualmente los costos caen por las diferentes competencias y de salarios entre los docentes presenciales y los tutores digitales que tienen en general menos formaciones y requerimientos de competencias disciplinarias. Los materiales instruccionales tienen una durabilidad mayor así como una mayor capacidad de actualización. Igualmente, ya existe un creciente mercado de compra e intercambio de cursos digitales que abarata el costo de los materiales al amortizarlos entre más estudiantes. 
Estas y otras causas más como la nueva competencia interuniversitaria, están incidiendo en que las ofertas de educación superior a distancia, formadas desde los años 70, estén lentamente avanzando hacia su transformación al incorporar tecnologías digitales y las prácticas pedagógicas que ellas permiten.

Tales transformaciones no se darán en todas las instituciones, ya que el pasaje de un modelo semipresencial abierto a uno virtual, tanto semipresencial como puro, si bien por un lado atrae nuevos estudiantes, por el otro expulsa aquellos de bajos recursos localizados en zonas y hogares de baja conectividad y recursos económicos. En estos casos, ello significa el no abandono de los modelos educativos semipresenciales, sino la incorporación de una nueva bimodalidad al interior de la educación a distancia.

Sin embargo, tanto el pasaje de un modelo de educación a distancia a otro, como la sola introducción del nuevo modelo virtual, implica una amplia reingeniería en las instituciones y en sus modelos educativos, que para su logro deben articularse a través de una planificación estratégica que permita introducir las amplias transformaciones que se requieren ya que ellas implican cambios en las competencias y actividades de los docentes, en el tipo de estudiante, en los procesos de aprendizaje, en los modelos de gestión, en las inversiones económicas y tecnológicas, en los materiales instruccionales y en las estructuras organizativas internas de la universidad.

La transformación de las instituciones de educación superior a distancia a partir de su virtualización y a un reposicionamiento competitivo, se fundamenta en promover un incremento de la cobertura, de la calidad, y a la vez una mayor disminución de los costos por alumno. El riesgo por su parte se asocia entre otros factores a los derivados de la pérdida de alumnos de las modalidades semipresenciales abiertas, de los costos políticos y económicos de la desarticulación de las redes de sedes presenciales, en las inversiones en infraestructura tecnológica, equipos humanos y capacitación de tutores, así como en los derivados de la digitalización de los recursos didácticos. En términos de cobertura, se logra una expansión a nuevos sectores de mayores ingresos económicos, y tal vez, mayores demandas diversificadas de campos de conocimientos donde se ha ofrecido una mayor cantidad de cursos que los modelos de educación abierta, ya que la digitalización permite que estas instituciones logren mayor diversidad de ofertas académicas. Igualmente la incorporación de tecnologías digitales, contribuye a normalizar y simplificar los procesos administrativos y abaratar los costos fijos por alumnos. Tal cambio además se ajusta a la generalización creciente del acceso a Internet por parte de la población en la región. 
Al tiempo, el nuevo escenario tecnológico, y por ende las nuevas estructuras de costos, dadas también las nuevas demandas de acceso por parte de sectores de mayores ingresos económicos, han planteado la irrupción de nuevos proveedores de educación superior a través de la educación a distancia los cuales tienden a ser privados con una creciente presencia de proveedores extranjeros. Ello plantea otro cambio, ya que a diferencia, mientras que en la primera oleada de la educación superior a distancia la presencia pública era dominante y todas eran ofertas locales, en el actual escenario, hay una preponderancia de oferta privada, junto con un aumento de la presencia de ofertas extranjeras, asociadas al aumento en la utilización de tecnologías digitales. Igualmente en el nuevo contexto se constata una mayor regulación pública así como una mayor diversidad de los modelos educativos al interior de la educación a distancia. En tal sentido, el cambio del modelo de educación a distancia hacia la virtualización aumenta, tanto la diferenciación, la calidad como la internacionalización, así como el grado de mercantilización por los costos superiores, más allá de que traslada costos de conectividad a los estudiantes y desaparece los costos de los envases físicos.

En esta fase se verifica como en la región se ha ido pasando muy rápidamente de modalidades homogéneas y monopólicas de ofertas de educación a distancia a través de las instituciones públicas de educación a distancia creadas o estructuradas en los 70 y en los 80, hacia un amplio, complejo y diverso escenario institucional y pedagógico, que a su vez se está expresando en un aumento significativo de la cobertura de la educación superior a distancia en la región. Ello se está dando en el marco de la diferenciación institucional que hemos referido tanto a nivel del sector público como privado asociado a cambios en las demandas y a diferenciación de los modelos educativos, que incentivan la despresencialización de la educación superior.

En este proceso visualizamos varios caminos. Por una parte la irrupción de nuevas ofertas de educación superior a distancia, y por el otro la transformación de las ofertas existentes de educación superior a distancia a partir de la incorporación de las tecnologías digitales y, en algunos casos, derivado de reingenierías institucionales y por ende cambios en los modelos educativos. Así, una de las manifestaciones es la nueva oleada de instituciones de educación superior tanto públicas como privadas como mecanismo para aumentar la cobertura a menos costos, en las cuales se desarrollan una variedad de modelos educativos. En algunos casos se reafirma el modelo abierto semipresencial pero sobre la base de una utilización de tecnologías virtuales. Los casos más significativos de política pública recientes han sido la Universidad Abierta de Brasil, los Centros Regionales de Educación Superior 
(CERES) en Colombia y la municipalización de la educación superior en Cuba. También en México se ha decidido crear una universidad a distancia. Ellos expresan modalidades diferenciadas de aumento de la cobertura ya no presencial, de acción pública directa y de articulación entre el Estado y las diversas demandas de acceso. Son además modalidades de acceso libre sin exámenes.

La otra orientación se focaliza en las complejas reingenierías de la educación superior a distancia que están desarrollando la mayor parte de las instituciones con programas de educación sobre la base de las tecnologías de la primera generación (libro y guías didácticas) o de la segunda (radio, telefonía o televisión), hacia nuevas modalidades que en distinta proporción van incorporando los nuevos ejes tecnológicos (Llorens, 1995). Ello ha sido significativo en los casos de UNED, UNA y UNAD que han avanzado hacia su virtualización.

\section{LA TENDENCIA A LA DESPRESENCIALIZACIÓN COMO EXPRESIÓN DE LA DIFERENCIACIÓN INSTITUCIONAL}

En la región se aprecia una fuerte diferenciación de las formas por las cuales se está produciendo la expansión de la educación a distancia. Tales diferenciaciones se dan a nivel a nivel de los países y de las instituciones. A nivel de los países, los marcos normativos, el peso de los diversos sectores así como los diversos niveles de acceso, equidad o consolidación de instituciones muestra una alta diversidad de modalidades como se detalla en el cuadro anexo.

\begin{tabular}{|c|l|}
\hline & $\begin{array}{l}\text { - Fuerte nivel de autonomía en las ofertas por parte de las Universidades con } \\
\text { un peso destacado de las ofertas localizadas a nivel de Facultades en forma } \\
\text { autónomas con modelos abiertos. }\end{array}$ \\
- Dinámicas de educación abierta con exámenes presenciales en las universidades \\
masivas públicas. \\
- Restricciones normativas a la oferta privada a partir de altos estándares de \\
exigencias de calidad y de requisitos de funcionamiento y múltiples exigencias \\
específicas. \\
- Carencia de políticas de estímulo en un contexto de alta cobertura de las \\
modalidades presenciales.
\end{tabular}




\begin{tabular}{|c|c|}
\hline Costa Rica & $\begin{array}{l}\text { - Expansión de la cobertura, incremento de la calidad con acreditación de las } \\
\text { ofertas de la Universidad Nacional de Educación a Distancia y su creciente } \\
\text { articulación con las universidades públicas del país en el marco de la } \\
\text { especialización de roles y cometidos al interior de las instituciones de educación } \\
\text { superior públicas y como modalidad de cobertura de las demandas no satisfechas } \\
\text { por las restricciones de acceso en el sector público presencial dado que es de } \\
\text { acceso libre. } \\
\text { - Reingeniería de la UNED hacia su transformación desde una institución a distancia } \\
\text { hacia una institución virtual de calidad con sus programas acreditados. }\end{array}$ \\
\hline Chile & $\begin{array}{l}\text { - Modelo de política pública fuertemente focalizado en la calidad que restringe la } \\
\text { educación formal a distancia. } \\
\text { - Tendencia a la oferta pública y privada no presencial hacia ofertas orientadas a la } \\
\text { capacitación. } \\
\text { - La virtualización de la enseñanza ha significado un acercamiento entre las } \\
\text { modalidades presenciales y a distancia, donde cada vez más las universidades } \\
\text { tradicionales ven a esta modalidad soportada en las TIC como una alternativa } \\
\text { viable para ser instrumentada a nivel de pre y postgrado de apoyo y de } \\
\text { complementación de los procesos de enseñanza. }\end{array}$ \\
\hline Colombia & $\begin{array}{l}\text { - Creación de Centros Regionales de Educación Superior en coordinación entre } \\
\text { el Ministerio de Educación y las Universidades en el marco de una compleja } \\
\text { situación política en el interior del país. } \\
\text { - Virtualización de las ofertas presenciales de instituciones de calidad. } \\
\text { - Conformación de una red de universidades privadas (Mutis) proveedoras de } \\
\text { educación virtual. } \\
\text { - Autonomización, expansión y reingeniería de la Universidad Nacional Abierta y a } \\
\text { Distancia a través de la virtualización y con ofertas de educación permanente. }\end{array}$ \\
\hline Ecuador & $\begin{array}{l}\text { - Expansión de modalidades semipresenciales de educación a distancia privadas y } \\
\text { también públicas para demandas locales y para migrantes en régimen pagante. } \\
\text { - Virtualización de las modalidades tradicionales de la educación a distancia } \\
\text { manteniendo el modelo híbrido de presencialidad en los exámenes. }\end{array}$ \\
\hline Honduras & $\begin{array}{l}\text { - Significativo peso de la matrícula a distancia en las dos instituciones públicas } \\
\text { (UNAH y UPFM) y lenta reingeniería al modelo de educación abierta hacia modelos } \\
\text { virtuales o semipresenciales con apoyo en web. }\end{array}$ \\
\hline
\end{tabular}




\begin{tabular}{|c|c|}
\hline México & $\begin{array}{l}\text { - Establecimiento de estándares de calidad al interior de las universidades } \\
\text { autónomas de la educación no presencial con los mismos parámetros que la } \\
\text { educación presencial. Incorporación de indicadores calidad en programas a } \\
\text { distancia. } \\
\text { - Creación de un amplio consorcio de las universidades públicas autónomas para } \\
\text { ofertar coordinadamente y bajo similares estándares programas de educación a } \\
\text { distancia tanto a nivel superior como medio. } \\
\text { - Creación de una Universidad a Distancia pública con asistencia de la UNED de } \\
\text { España y apoyo a la oferta virtual por parte del sector público como mecanismo de } \\
\text { que promueva la ampliación de la cobertura, fundamentalmente en el bachillerato. } \\
\text { Tendencia al ofrecimiento por parte de las Universidades privadas de ofertas } \\
\text { virtuales o a distancia orientadas a la educación permanente o hacia sectores de } \\
\text { bajos ingresos a partir de apoyos y subsidios financieros del gobierno. }\end{array}$ \\
\hline Panamá & - Creación de dos universidades privadas a distancia. \\
\hline Perú & $\begin{array}{l}\text { - Estructuración de redes pedagógicas a distancia como mecanismo para articular } \\
\text { la alta creación de sedes y subsedes locales por parte de algunas universidades } \\
\text { privadas. } \\
\text { - Desarrollo de estándares de evaluación o para instituciones de educación a } \\
\text { distancia. } \\
\text { - Desarrollo de universidades focalizadas en la oferta a distancia (ULADECH) }\end{array}$ \\
\hline Rep. Dominicana & $\begin{array}{l}\text { - Creación y desarrollo de dos universidades focalizadas en modelos } \\
\text { semipresenciales (Universidad del Caribe - UNICARIBE, y Universidad Abierta } \\
\text { para Adultos - UAPA). } \\
\text { - Aprobación de un reglamento de la SEESCyT de funcionamiento de las } \\
\text { instituciones de educación a distancia. }\end{array}$ \\
\hline Venezuela & $\begin{array}{l}\text { - Modalidad de acceso libre del sector público para sectores de bajos ingresos que } \\
\text { no pudieron acceder a la educación presencial pública. } \\
\text { - Lento proceso de reingeniería de la Universidad Nacional Abierta. }\end{array}$ \\
\hline
\end{tabular}

Cuadro 2. Diferenciación nacional de la oferta de educación a distancia

Se visualiza como la región ha ido pasando muy rápidamente de modalidades homogéneas y monopólicas de ofertas de educación a distancia a través de las instituciones públicas de educación a distancia creadas en los 70 y 80 a un amplio, complejo y diverso escenario institucional público y privado, que es el eje de la creciente expansión de la cobertura y de la multiplicidad de modalidades pedagógicas a distancia. Es este un proceso de diferenciación institucional tanto a nivel del sector público como privado en el marco de la creación de un nuevo eje dinámico de la educación superior en la región a través de la despresencialización de la educación superior. Destacamos en esta diferenciación, más allá de las referidas a las instituciones externas, varias expresiones a través de las cuales se está produciendo la expansión de la educación a distancia regional. 


\section{Las tradicionales Universidades públicas}

Uno de los componentes de la diferenciación, y que está influyendo significativamente en la expansión de la educación no presencial, es la estrategia de muchas universidades públicas para aumentar su cobertura, reducir el peso de las demandas insatisfechas, y relegitimarse como ámbitos de equidad a través de un incremento de la oferta a distancia, dada la incapacidad de seguir incrementando la matrícula presencial y de la necesidad de encontrar mecanismos para derivar la saturación de las aulas. Las grandes universidades autónomas tradicionales de la región, que hoy tienen las más fuertes restricciones al ingreso automático se han caracterizado por un modelo educativo presencial. Sin embargo, como derivación de las presiones políticas de la demanda permanente de los bachilleres sin cupo, de su tradicional rol institucional de canalización de las demandas sociales, de las presiones de los grupos académicos para la incorporación de tecnologías, así como de los problemas derivados de la pelea de los presupuestos públicos asociados a los niveles de cobertura, algunas de ellas han comenzado a incursionar en ofertas no presenciales y han ido construyendo un modelo bimodal. Muchas de estas iniciativas se están actualmente virtualizando.

La Universidad Nacional Autónoma de México (UNAM) por ejemplo marcó un modelo que se generalizó a todo México, cuando al mismo tiempo que estableció restricciones de acceso en los 70, dio nacimiento a la educación a distancia a través de modelos semipresenciales en contextos bimodales. Ello no se dio sólo en instituciones con barreras de ingreso. La Universidad Nacional Autónoma de Honduras (UNAH) también desde los 80 desarrolló un modelo de educación a distancia abierto que alcanzó al 9\% de su matrícula. En Uruguay y Argentina, la UDELAR y la UBA tienen una parte significativa de su matrícula a través de sistemas "abiertos" por los cuales, dada la saturación de las aulas y la ausencia de restricciones de ingreso, muchos alumnos no asisten a clases, sino que desarrollan prácticas de autoestudio en forma autónoma y simplemente asisten a la Universidad a rendir las pruebas en algunos de sus cursos.

Dado el fuerte peso de los gastos corrientes y los relativamente bajos salarios, muchas universidades públicas con saturación en las aulas tienen fuertes restricciones para derivar fondos hacia inversiones y hacia equipamientos tecnológicos, y por ende hacia la educación virtual, lo cual en muchos casos ha reforzado que las ofertas de educación no presencial se financien a través de las matrículas. Tales ingresos adicionales han fungido además como mecanismos de compensación salarial a los docentes, al ser contratados por trabajos puntuales y ser adicionales a sus sueldos 
en la institución. Tal es por ejemplo el caso de la Universidad Central de Ecuador, cuyos estudiantes de la Facultad de Ciencias Administrativas que no acceden a los cupos presenciales pueden cursar la carrera en forma no presencial y pagante. La Universidad de Quilmes en Argentina, también tiene ofertas a distancia pagantes, siendo las presenciales de acceso abierto y gratuitas. En los inicios estas modalidades y ofertas estaban muy focalizadas y con escalas reducidas, pero con los años han pasado a tener mayores coberturas, aun cuando prima dominantemente el modelo presencial en estas instituciones.

El caso más llamativo se ha dado en México, donde la UNAM, desde los 70, cuando se inició tal modalidad asociada a las restricciones de acceso presenciales, al establecer un ingreso selectivo en función de calidad a través de pruebas de conocimientos. Sin embargo, al mismo tiempo, se impuso una modalidad de educación a distancia con los mismos programas, los mismos estándares de calidad y con sus propios requisitos de acceso selectivos. Además de esta orientación única en la región de un perfil de calidad de la educación a distancia, México, manifiesta también una particular tendencia a la consorciación de la oferta educativa a distancia del sector público autónomo, en el marco de una estrategia permanente de la UNAM de establecer alianzas con las mayores universidades públicas del país y a servir de centro de referencia de calidad. Ello se ha observado en la creación del Consorcio Clavijero y en la reciente creación de un Consorcio de las Universidades autónomas públicas, el Espacio Común de Educación Superior a Distancia (ECOESAD) con mayor oferta en educación a distancia, y que ha recibido un fuerte apoyo gubernamental. ${ }^{2}$

El ECOESAD busca promover la educación superior como un bien público ya que es casi gratuito y unifica los esfuerzos de varias de las instituciones de educación superior pública con altos estándares de calidad. De hecho actúa como núcleo promotor para extender la propuesta e incluir a otras instituciones del país. Nació en el 2004, de convenios entre 8 universidades fundadores y hoy incluye a decenas de universidades públicas, en los cuales se coincidió en la necesidad del reconocimiento mutuo de créditos, del intercambio estudiantil en licenciatura y postgrado, de la creación de programas compartidos, del desarrollo de una oferta educativa en la modalidad a distancia, de la elaboración conjunta de publicaciones electrónicas y de un portal en la Internet. La creación del Espacio Común de Educación Superior a Distancia (ECOESAD) tiene como objetivo general, conformar un consorcio de universidades para el desarrollo de la educación superior a distancia, que permita integrar la oferta que cada Institución ha elaborado para compartirla a nivel nacional. Este consorcio para algunos es la génesis de una universidad nacional de educación a distancia en México (Amador, 2007). Sin embargo, el gobierno ha creado en el 
2009 la Universidad A Distancia de México, mostrando a futuro un fuerte eje de un modelo nacional de desarrollo de la educación a distancia público sobre dos ejes, uno más autonómico sistémico y otro oficial. En otros países como Argentina, con fuerte nivel de regionalización, ello también se ha estado desarrollando. ${ }^{3}$ Otros desarrollos al interior de este tipo de Universidades han estado asociados a la formación a sus docentes ante las restricciones presupuestarias que imposibilitan becas y sabáticos (UCV) y como mecanismo que permitan posteriormente mejorar los niveles salariales al facilitar los recorridos académicos establecidos en las normas de carreras administrativas y académicas.

Algunas otras instituciones públicas, sobre todo las del interior de los países, han utilizado directamente estas modalidades pedagógicas como mecanismo de incrementar su cobertura y también rentas dadas la imposibilidad legal de lograrlo para los servicios presenciales (Universidad Nacional Faustino Sánchez Carrea- Perú o la Universidad de Los Lagos en Puerto Mont-Chile), así como también algunas Facultades (Universidad Central del Ecuador o la Universidad del Centro de la Provincia de Buenos Aires en Argentina) cuya modalidad de acceso a la educación a distancia no está asociada a restricciones de acceso a las modalidades presenciales.

\section{Las universidades a distancia públicas}

En los 70, acompañando el establecimiento de restricciones al acceso abierto a las Universidades públicas en la región, se desarrolló la oferta de educación a distancia a través de la creación de instituciones de educación públicas. Ellas fueron la Universidad Nacional Abierta (UNA) de Venezuela, la Universidad Nacional de Educación a Distancia (UNED) de Costa Rica, y la Universidad Nacional Abierta y a Distancia (UNAD) de Colombia, y se basaron en el modelo de la Open University de Inglaterra. ${ }^{4}$ Estas instituciones de países en los cuales las restricciones de acceso a la educación pública fueron significativas, y a través de las cuales se buscó facilitar los accesos gratuitos a la educación superior, se basan en una libertad de acceso y propendían a pasar de un control del acceso a un control en el egreso, invirtiendo los estándares ya que el eje de la calidad no se articulaba sobre requisitos de ingreso sino de generación de niveles de calidad en el proceso de enseñanza. La Open University promovía un tipo de enseñanza sobre la base de calificaciones de salida, no importando el nivel de los estudiantes en su incorporación a la universidad sino su buena calificación final. En la región el objetivo primordial no descansó en la calidad de los procesos sino en el aumento de la cobertura. Con el fin cumplir esa orientación las instituciones de la región abrieron sedes y subsedes por todos sus países 
respectivos, se transformaron en grandes editores de materiales instruccionales en tanto su modelo pedagógico se basaba en guías y textos de estudio y en el apoyo a los estudiantes a través de tutores. Rápidamente promovieron una expansión de la cobertura de bajo costo a través de sus múltiples subsedes, fueron casi monopólicos en sus países durante largos años, se focalizaron en sectores de bajos ingresos económicos que no podían acceder a la educación superior ni pública ni privada por sus restricciones de calidad y costo, y se basaron en modelos de educación a distancia abiertos y semipresenciales con apoyo de materiales instruccionales, asistencia tutorial y exámenes presenciales.

La irrupción de las tecnologías de comunicación e información desde los noventa han planteado a estas instituciones como hemos analizado su posible transformación desde instituciones de educación a distancia basadas en el uso de las tecnologías de la primera y de la segunda generación, hacia instituciones basadas en tecnologías con mayor intensidad de tecnologías digitales.

El avance hacia la virtualización de estas instituciones ha sido aún pequeño, ya que por ahora los cambios son de tipo institucional, pero marcan un claro camino de ampliar su base tecnológica y su tipo de oferta. La Universidad Abierta de Venezuela por ejemplo si bien alcanza a 60,000 alumnos, con fuertes tasas de abandono, deserción e imprecisión de la categoría de estudiante, ya tiene dos cursos a nivel de especialización virtuales con nuevos tipos de alumnos y nuevas lógicas pedagógicas que funcionan como ámbitos de experimentación. En este caso, la virtualización se focaliza en postgrados de mayor calidad totalmente virtuales, en tanto se mantienen las dinámicas más tradicionales de la educación a distancia en el pregrado con modelos semipresenciales abiertos. La Universidad Nacional de Educación a Distancia (UNED) de Costa Rica, con 25 mil alumnos, ha resuelto en el 2006, luego de varios años de mantener ofertas virtuales y semipresenciales abiertas, avanzar definitivamente hacia un modelo totalmente virtual que incluye además procesos de acreditación, mejoría de los materiales instruccionales y aumento de cobertura internacional. La UNAD, que tienen 18.899 alumnos de pregrado y 37.023 en total por el peso de la educación continua en sus 55 sedes en Colombia y una en Miami, en general sigue el modelo a distancia aunque avanza hacia un fuerte proceso de virtualización en la búsqueda de formar a los emigrantes colombianos en el exterior, pero también se expande hacia la educación permanente con lógicas digitales. En este caso la Universidad muestra una expansión de la cobertura por la vía de una oferta orientada a actualización de competencias que ya representan el 48,9\% de su matrícula (Facundo, 2007). 
En términos generales, la UNAD tiende a un modelo bimodal a distancia, ya que ofrece dos mediaciones pedagógicas: la educación a distancia a través del Campus Virtual, o mediante el sistema tradicional semipresencial. La diferencia radica en el menor o mayor uso de tecnologías, y la decisión depende del estudiante y de sus accesos tecnológicos, en los casos en los cuales los cursos se ofrecen simultáneamente por el sistema tradicional, y el virtual. Bajo esta mediación el acceso a los contenidos didácticos, los procesos de aprendizaje y el acompañamiento tutorial se realizan a través del Campus Virtual. Para el desarrollo de cursos a través de la medicación tradicional, la UNAD cuenta con cerca de 40 Centros de Educación a Distancia CEAD de su propia red, y 16 CERES (Centros Regionales de Educación Superior), en los cuales encuentras procesos de acompañamiento tutorial de manera presencial programados periódicamente.

Los procesos de virtualización de estas instituciones, que han alcanzado una matrícula combinada de 145 mil estudiantes (casi el 1\% de la matricula total regional de educación superior), tienen sin embargo diversas dificultades en sus reingenierías por las tensiones internas vinculadas a las normas, contratos laborales e infraestructuras, así como externos, asociados a los sectores sociales que cubre y a las carencias por parte de estos de equipamientos informáticos así como a su localización geográfica en zonas de baja conectividad en sus geografías nacionales, lo cual ha derivado que si bien todas han establecido estrategia y políticas orientadas hacia una mayor virtualización, también mantiene diversos componentes presenciales. ${ }^{5}$

La expansión de estas instituciones también está asociada al costo de estas modalidades educativas que son sensiblemente inferiores a la educación presencial.

\begin{tabular}{|l|c|c|c|}
\hline & UNA (1) & UNED (2) & UNAD (3) \\
Transferencia por alumno & 1.140 & 438 & 626 \\
Transferencia promedio nacional de las universidades públicas & 5.391 & 1.573 & 4.070 \\
Transferencias por alumno a la Universidad más costosa & 12.890 & 2.156 & 11.494 \\
Relación entre la transferencia media por alumno a la universidades & 4,72 veces & 3,59 veces & 6,50 veces \\
públicas frente a la transferencia a la universidad a distancia & & & \\
\hline $\begin{array}{l}\text { Relación entre la media de transferencias por alumno a la universidad de } \\
\text { mas calidad y de elites y a la universidades a distancia }\end{array}$ & 11,3 veces & 4,92 veces & 18,36 \\
\hline
\end{tabular}

Cuadro 3. Costos de la Educación Abierta en comparación con la Educación Presencial

Nota: 1. En el caso de la UNA de Venezuela los costos están en millones de bolívares a precios corrientes del 2005. La institución más costosa es la Universidad Simón Rodríguez. 2. En el caso de la UNED de Costa Rica los costos están en miles de colonos para el 2006. La institución más costosa es la Universidad de Costa Rica. 3. En el caso de la UNAD de Colombia los costos están en miles de pesos del 2006 y la Universidad más costosa 
es la Universidad Nacional de Colombia. Los datos refieren las transferencias públicas y no son comparables dada la diferencia de la paridad de los poderes de compra. Los datos de la UNED, vienen del Informe CONARE, para UNA del Plan Estratégico de la Universidad, y para la UNAD del SINIES analizados por el Observatorio de la Universidad Colombiana.

\section{Las nuevas modalidades de acceso públicas en la región}

Una de las expresiones de la expansión de la educación a distancia es a través de nuevas modalidades institucionales del sector público. Los casos más significativos de fuertes políticas públicas recientes de promoción de la educación a distancia se han dado con la creación de la Universidad Nacional Abierta de Brasil, con los Centros Regionales de Educación Superior en Colombia y con la municipalización de la educación superior en Cuba que tiene fuertes componentes semipresenciales. La reciente iniciativa mexicana se inserta en este escenario. Ellas expresan modalidades diferenciadas de promover el incremento de la cobertura no a través de las mismas modalidades tradicionales de acceso presenciales fundamentalmente por eficiencia de costos.

\section{La Universidad Abierta de Brasil}

Sinlugar a dudas, en Brasil seestá realizandola apuesta más consistente en la región desde el sector público para promover una oferta a distancia o virtual, tanto a través de flexibilización de la oferta privada, como de la creación de una institución pública ejecutora de una compleja articulación de múltiples ofertas públicas. Igualmente, bajo este impulso se creó un viceministerio específico para regular y supervisar la educación no presencial. En Brasil, se fue formando una demanda insatisfecha por educación virtual, dadas sus características geográficas como continente, que fue represada durante mucho tiempo por la política pública. En un tiempo las normas regulatorias han sido duramente criticadas por la Asociación Brasileña de Educación a Distancia (ABED), argumentando que el Ministerio de Educación y Cultura de Brasil "tiene aprobado apenas 120 o 130 pedidos de reconocimiento, y admite que posee más de 4.000 solicitudes de diversas universidades que esperan de esta autorización para iniciar cursos a distancia”. Ello cambió en pocos años. A partir del 2001 con la Reglamentación 2253, el Ministerio de Educación permitió que hasta el 20\% de la carga horaria de los cursos presenciales de los programas autorizados por el propio Ministerio de Educación pudieran ser ofrecidos bajo la modalidad a distancia por esas mismas instituciones educativas, lo cual significó el inicio de una fuerte expansión de las modalidades híbridas con diversos seguimientos en web y 
tutorías.

A su vez desde el 2004 hubo otro impulso adicional a la virtualización de la educación a partir de la creación de la Universidade Aberta do Brasil (UAB). Esta institución que es cabeza organizadora, promotora y financiadora de la oferta pública de educación a distancia en Brasil, en el 2007 comenzó a ofrecer mas de 61.575 plazas, en el marco de un proyecto que incorporó a 50 instituciones federales de enseñanza superior y 427 municipios y Estados, que se inscribieron a principios del 2006, para participar como los 297 polos de la Universidad Abierta del Brasil (UAB), y que ofrecen cerca de mil trescientos cursos a distancia, la mayoría de graduación en diversas áreas del conocimiento. Del total de los cursos, 690 son de licenciatura, 357 de postgrado en "lato sensu" (especializaciones o diplomados de cuarto nivel), 186 de bachillerato, 54 tecnológicos, 12 secuenciales y siete de maestría, que corresponden a 50 instituciones federales de enseñanza superior - 40 universidades e diez centros de educación tecnológica - y 427 prefecturas y gobiernos.

\section{Los Centros Regionales de Educación Superior de Colombia}

Otro caso altamente significativo es la creación y fuerte expansión de los Centros Regionales de Educación Superior (CERES) en Colombia como parte de una estrategia para desconcentrar oferta y ampliar cobertura, en el marco de los conflictos políticos en el interior y que han restringido la capacidad de las Universidades de regionalizarse. ${ }^{6}$. Actualmente ya hay 100 centros, que son lugares dotados de infraestructura tecnológica de información y comunicación, en el cual la comunidad puede acceder a programas de educación superior técnica profesional, tecnológica y universitaria, que ofrecen las diversas instituciones de educación superior: 32 de ellos están bajo supervisión de la UNAD, y otra parte de ellos bajo supervisión de las Universidades de la Red Mutis, las cuales tienen una asistencia técnica del Tecnológico de Monterrey.

No son una gran edificación, ni tampoco la sede de una universidad o su propio centro de educación a distancia. Ellos están dotados de una mínima infraestructura física, están soportados por una fuerte conectividad que les permita acceder a bibliotecas, prácticas de laboratorio y talleres, según lo requieran los programas. En su funcionamiento diario cuentan con el soporte académico y técnico de una institución de educación superior "operadora" a la cual se le dio la gestión, que facilita tanto el aprendizaje del estudiante como también apoya a otras instituciones de educación superior que ofrecen programas a la comunidad en ese Centro. Es una red de instituciones trabajando en ofertar educación virtual y a distancia y 
la vez asumiendo la responsabilidad de la gestión de algunos de estos centros. La Universidad Nacional Abierta y a Distancia (UNAD) es parte de este modelo y ella administra algunas de estas subsedes y que también se formaron en su propia red nacional. Cada CERES nace de una alianza regional que congrega al Gobierno, a la sociedad civil y a la academia, con aportes distintos y complementarios, con el propósito común de llevar a una población, a través de la educación superior, oportunidades de desarrollo social, económico y humano. Ellos se ubican en lugares geográfica o socialmente marginados, y los programas que brindan deben ser pertinentes para la región y acordes con el mercado laboral, propendiendo a motivar a los jóvenes a permanecer en su lugar de origen por lo que sus programas deben ser resultado de un análisis de los requerimientos específicos de la zona de influencia en términos de demandas y competencias requeridas. Cada programa académico recibe recursos públicos del Ministerio de Educación, con el fin de viabilizar esta educación a distancia, altamente descentralizada, gestionada por parte de instituciones públicas o privadas, pero que pretende facilitar las ofertas de todo el sistema de educación a distancia tanto nacional como global.

El gobierno de Colombia está empeñado en impulsar la cobertura en educación superior a través de los CERES, especialmente en zonas rurales en convenios con gobernación, alcaldía y cajas de compensación, entre otras, y en donde pueden llegar las instituciones de educación superior a ofrecer sus carreras. En el año 2006 había 83 funcionando con una matrícula de 13 mil estudiantes. En el 2007 se llegó a 1000 centros y se espera alcanzar una meta de 50 mil estudiantes. El gobierno considera que esto es más efectivo y económico que impulsar la regionalización de universidades públicas. Adicionalmente en el marco de una estrategia nacional de aumentar la cobertura, según la Presidencia de la República, la Universidad Nacional Abierta y a Distancia (UNAD), debe pasar de 37.500 estudiantes que tenía en 2007 a 60 mil en 2.010.

\section{La municipalización de la educación superior en Cuba}

Cuba se constituye en los últimos años en otro caso significativo de utilización intensiva de las modalidades a distancia semipresenciales para expandir la cobertura. Además de los cursos regulares diurnos presenciales con exámenes de acceso y cupos, los cuales a su vez garantizan un empleo profesional oficial al concluirlos, en Cuba desde el 2000 se han abierto nuevas modalidades de acceso a nivel de pregrado a la educación superior, consistente en cursos regulares para los trabajadores, dirigidos o de enseñanza libre. Los cursos regulares para trabajadores se han modelado para 
una dedicación parcial de tiempo, de manera que permitan realizar los estudios manteniendo el vínculo laboral. La educación de estos cursos es por lo general de un año más con respecto a los diurnos. Los cursos dirigidos denominados también de enseñanza libre no prevén relaciones sistemáticas entre profesores y estudiantes y se apoyan fundamentalmente en la preparación autodidacta del interesado con la ayuda de textos y guías de estudios complementarias, además de determinadas asesorías ofrecidas por profesores.

El proceso de continuidad de los estudios es la forma en que actualmente se expresa la municipalización de la educación superior. Se ha diseñado con un currículum flexible donde el estudiante después de su jornada laboral, recibe clases y orientaciones con una frecuencia de dos o tres veces por semana. El curso no tiene apoyo en web sino en medios audiovisuales, libros y otros materiales docentes, y en especial, con la atención de un tutor que sigue y apoya el desarrollo del aprendizaje del estudiante a lo largo de su carrera.

Mayoritariamente esta modalidad se caracteriza por ofertas de cursos nocturnos, para personas que están trabajando, sin becas, con mecanismos de accesos competitivos y fundamentalmente son de estudios de dos años, aunque ya se están expandiendo cursos de licenciados de cinco años pero utilizando más profesores de tiempo parcial e infraestructuras de múltiples instituciones educativas y no educativas, en un sistema abierto que ya alcanza a más de 350 Sedes Universitarias Municipales. ${ }^{7}$ Este sistema además tiene criterios, guías y procedimientos de evaluación y acreditación propios.

La municipalización en sus inicios era fundamentalmente presencial, pero crecientemente está incorporando modalidades pedagógicas semipresenciales. Adicionalmente existe un sistema de educación a distancia basada en libros de texto y guías, que se conformó como un sistema de acceso abierto para todos y que tampoco da derecho a un puesto de trabajo sino que está dirigido a personas ya insertas en dinámicas laborales así como para su oferta en el extranjero como parte de la política de internacionalización de la educación superior cubana que propende a construir redes académicas y a generar divisas. La fuerte inversión en capital humano local, bajos salarios, y demandas de divisas, facilita la internacionalización de la educación superior, una de cuyas modalidades son los postgrados internacionales semipresenciales. 


\section{Las Universidades privadas}

En la región, mientras que al comienzo la oferta a distancia era solo pública, tal vez con la excepción del Tec de Monterrey, se constata un creciente corrimiento hacia un mayor peso del sector privado, dadas las potenciales rentabilidades, la existencia de demandas insatisfechas, el agotamiento del potencial de crecimiento dada la cierta saturación de la oferta de educación presencial en algunos países de la región. Se verifica una transición desde lo público a lo privado también por las flexibilidades que estas modalidades requieren y para las cuales el sector privado tiene más posibilidades administrativas. Si bien hay un peso importante de algunas universidades privadas localizadas en las capitales de los países, como por ejemplo la Universidad del Caribe en Santo Domingo, es sin embargo particularmente significativo destacar que muchas de las nuevas ofertas han provenido de universidades privadas del interior de los países, donde sus posibilidades de expansión bajo ofertas presenciales eran muy bajas. Muchas universidades privadas del interior de los países de la región se han especializado y posicionado en nichos de ofertas focalizadas en educación no presencial, tanto a distancia comovirtual para estudiantes locales o para sus emigrantes como mecanismo para aumentar su cobertura y rentabilidad. Inversamente también lo han realizado las instituciones localizadas en las grandes ciudades para lograr aumentar su presencia en ciudades pequeñas con bajas posibilidades de realizar ofertas presenciales. Este doble proceso ha promovido un complejo entramado de alianzas que se han desarrollado junto también a la representación o la articulación con ofertas transfronterizas internacionales de educación virtual. Las ofertas privadas han contribuido a la diferenciación institucional y han abierto un espacio de competencia público-privado en este sector. Tales ofertas han estado asociadas además a la vocación internacional de estas instituciones, a sus necesidades de crecimiento para escalas mínimas rentables, a la ausencia de restricciones a la oferta no presencial en sus países, a la existencia de emigrantes en el exterior que se constituyen en una demanda potencial significativa, así como a la propia saturación de los mercados presenciales y a la búsqueda de nichos rentables de negocios. Tales procesos tienen además apoyos en las empresas productoras e importadoras de bienes y servicios de comunicación e información orientados a la producción de ofertas no presenciales y en los organismos internacionales que siempre visualizan positivamente ofertas y dinámicas supranacionales.

Entre las universidades de educación a distancia del interior de los países, podemos referir, con muy diferentes modelos pedagógicos, a la Universidad Técnica Particular de Loja (Loja, Ecuador) ${ }^{8}$, a la Universidad Belloso Chacín (Maracaibo, Venezuela) $^{9}$, a la Universidad Católica (Salta, Argentina) o a la Universidad Blas 
Pascal (Córdoba, Argentina) ${ }^{10}$, al Tecnológico (Monterrey, México), a la Universidad Abierta para Adultos (Santiago de los Caballeros, República Dominicana), a la Universidad Autónoma de Bucaramanga (Bucaramanga, Colombia) ${ }^{11}$, la Universidad de Paraná en Brasil y la Universidad de los Ángeles (Chimbote, Perú). Aún cuando las estrechas demandas pueden reforzar a las instituciones del interior de los países a ofertar educación a distancia para alcanzar mayores coberturas, sin duda es también significativo la realización de ofertas a distancia por parte de instituciones localizadas en las capitales de sus países como mecanismos para poder cubrir y satisfacer las demandas al interior de los países, dado que en esas regiones se carece de escala para el funcionamiento de instituciones presenciales. Tal ha sido el caso por ejemplo de las universidades Garcilazo de la Vega y Alas Peruanas en Perú, de la Universidad Abierta de Panamá, de la Universidad Real de Bolivia y la Universidad del Caribe de República Dominicana, que en este segmento es de las más importantes y coherentes en su modelo pedagógico de gestión, así como también de las primeras en la región sobre la base de una oferta semipresencial en términos de matrícula.

\section{LAS TENDENCIAS DOMINANTES DE LOS PROCESOS DE VIRTUALIZACIÓN EN LA REGIÓN}

Las estadísticas muestran claramente el aumento de la matrícula incentivado a su vez en la amplia diversidad de modalidades institucionales. A partir de la proyección de diversos estudios se puede asumir una hipótesis de crecimiento bajo que permitiría pensar la existencia de unos 984 mil estudiantes bajo modalidades híbridas que representarían el 6,4\% de la matrícula regional de América Latina para el año 2005, que permiten afirmar que la educación a distancia, o las modalidades despresenciales de la educación superior ya se han conformado como una nueva realidad importante del panorama de la educación superior en la región y cuyas tasas de incrementos son muy superiores a las tasas de expansión históricas de la educación tradicional presencial. Ello como derivación del desarrollo de un nuevo modelo socio económico y tecnológico, así como de demandas de flexibilidad, mejores niveles de calidad de las ofertas, virtualización de la educación a distancia resultado de complejas reingenierías tecnológicas y organizacionales, mayores ofertas públicas por la eficacia de menores costos así como de proveedores internacionales, todo lo cual permite canalizar y facilitar estas demandas de amplios sectores de América Latina que buscan acceder a la educación como instrumento de mejoramiento de sus oportunidades. En este marco se espera que en los próximos años, se incremente la propia diversidad de modalidades institucionales y organizativas. En el marco de esas nuevas realidades en la región se verifican algunas prospectivas que parecen verificarse en la educación a distancia en la región. 


\section{Hibridización de las modalidades pedagógicas}

La tendencia a la despresencialización de la educación superior, se articula a través de componentes presenciales y una multiplicidad de modalidades de la 1,2,3 y 4 generación de la educación a distancia. Son tanto modalidades pedagógicas como tecnológicas de tipo híbridas, que combinan en muy diversa proporción dinámicas de enseñanza-aprendizaje presenciales junto con componentes no presenciales tanto virtuales, a distancia o abiertos. Igualmente también tecnologías analógicas y digitales, junto con una diversidad de materiales instruccionales planos, interactivos y de simulación. La introducción de este nuevo modelo mixto con sus propias características es el resultado de las múltiples tensiones entre los diversos impulsores y restrictores nacionales e internacionales cuyas presiones están determinando finalmente las características de la hibrides de educación a distancia de la región.

La hibridización derivaría fundamentalmente de los marcos normativos y de concepciones académicas que han incorporado el mantenimiento de componentes presenciales, sobre todo de los exámenes. En muchos casos, tales regulaciones imponen que las megauniversidades están obligadas a fraccionar los procesos educativos en componentes nacionales presenciales (en general los exámenes) e internacionales virtuales (el proceso de enseñanza).

\section{Fraccionamiento internacional}

Las tecnologías de comunicación e información permiten el fraccionamiento de los procesos educativos a escala internacional, el cual es utilizado intensamente por las megauniversidades de los países centrales, dadas las diversas escalas de costos, las diversas restricciones normativas en los países de la región a la utilización exclusiva de modalidades virtuales, como a una dinámica de mercadeo que se basa en la utilización intensiva de postgrados mixtos, sándwiches o en franquicias con componentes virtuales y también componentes presenciales asociados a la movilidad estudiantil.

Asociado a la posibilidad técnica del fraccionamiento de los procesos educativos, la localización de tutores, gestores o administradores, se consolida en función de los diferenciales salariales de estos docentes y de los países y regiones desde los cuales ejerzan su trabajo, lo cual es también la base sobre la cual se tejen múltiples alianzas ínter universitarias. Este fraccionamiento, se produce con más intensidad en el postgrado ante la incapacidad de ofertar localmente todas las opciones disciplinarias, y se asocian a la creciente movilidad académica docente y estudiantil, lo cual reafirma las ofertas globales dentro de modelos híbridos. 
El fraccionamiento de los procesos de educación virtual es una variable meramente técnica impuesta por las tecnologías, pero el eje que determina la aceptación y la intensidad en el uso de esta modalidad está asociado a la movilidad en los procesos de enseñanza-aprendizaje y las normas locales, más que a los criterios de calidad. La existencia de mecanismos de regulación para los proveedores externos, criterios generales de autorización o estándares regionales de evaluación y acreditación contribuyen a imponer ese fraccionamiento. Dentro de este apartado incluimos acuerdos entre varias instituciones cuando se incluye aportes y roles diferenciados internacionalmente de las diversas instituciones.

\section{Mercantilización}

La oferta internacional como muchas de las ofertas locales se ha expandido bajo formas de pago. Algunas universidades públicas usan inclusive esta modalidad como mecanismo de generación de recursos, como por ejemplo la Universidad de Quilmes o la Universidad Central de Ecuador. En otros casos, las ofertas virtuales tienen costos de matrículas superiores que los precios de las matrículas semipresenciales, como en el caso de la UNA de Venezuela. Los volúmenes de capitales comprometidos, su focalización en los niveles de postgrado o en cursos de actualización, así como por el propio peso de la oferta privada nacional e internacional han contribuido a que esta nueva modalidad de acceso a la educación superior se esté realizando bajo mecanismos de pago. Sin embargo, en las nuevas ofertas públicas y en aquellas que proceden de las universidades públicas autónomas, la educación a distancia se basa en su casi gratuidad, dado que estas ofertas se focalizan en permitir los niveles de equidad en el acceso que no se pueden realizar bajo las modalidades presenciales. Funcionan como sistemas de compensación casi gratuitos. Por su parte en las Universidades a distancia tradicionales donde el acceso era fuertemente subsidiado en tanto el peso dominante era de sectores de bajos ingresos, se constata que al avanzar hacia modelos a distancia dominantemente virtuales y hacia un incremento de la calidad, se aumentan los precios de las matrículas y se posicionan en segmentos sociales de mayores ingresos. En algunos de estos la gratuidad anterior estaba asociada a muy bajos costos de la educación por alumnos y a bajos niveles de calidad.

\section{Diferenciación y consorciación de las ofertas}

La educación a distancia en la región se está expandiendo a través de una alta diversidad de modelos pedagógicos y tecnológicos, que han derivado en una alta diferenciación de las instituciones y de sus orientaciones. Entre una de sus diferenciaciones se constata la creación de un elevado nivel de consorciación de 
las ofertas. Mientras que en las modalidades presenciales en la región no se ha producido significativos procesos de alianzas o de trabajos compartidos entre las instituciones, en la educación a distancia se verifica crecientemente la realización de convenios o alianzas de intercambio o adquisición de recursos entre esas las diversas instituciones. En la región, dada las escalas y la mayor capacidad técnica de trabajar compartidamente, se están creando nuevas modalidades de alianzas inter universitarias. Entre estas destacan los consorcios multi-institucionales para ofertar educación virtual entre los cuales destacan la UVirtual (Chile), y el Consorcio Clavijero (México). Inclusive en este país se ha creado un Consorcio de Universidad Públicas para la Educación a Distancia (ECOESAD) para coordinar las ofertas, abrir cursos conjuntos y proponer posibilidad de una movilidad virtual. Inicialmente bajo el Politécnico, UNAM, Veracruzana, Guadalajara y León, se ha ido ampliando a más universidades públicas exclusivamente dado que sus matrículas son totalmente subsidiadas. En el sector privado ello también se está produciendo pero con menor intensidad. Tales son los casos de la Red Mutis en Colombia, la cual además se articula con el Tecnológico de Monterrey. La propia Universidad Abierta de Brasil es de hecho un consorcio de cientos de instituciones tanto universitarias como no universitarias que ofrecen cursos de EaD articulados bajo parámetros comunes.

\section{Creación de regulaciones}

Se constata en la región el avance de los procesos de establecimiento de criterios normativos y de aseguramiento de la calidad para las modalidades de educación no presenciales. Ellotanto comoresultadodelanecesidad deestablecermarcos regulatorios a una realidad en crecimiento como a su vez de la necesidad de establecer estándares que regulen el ingreso de las ofertas transfronterizas. En este proceso se comienzan a sentar las bases de regulaciones globales de la educación a distancia, en cuanto refieren tanto a los países desde los cuales se emite como a aquellos en los cuales se oferta. Sin bien aún nos encontramos en los inicios de la conformación de normas nacionales, se aprecia en las discusiones y en las declaraciones gubernamentales la necesidad de avanzar hacia marcos normativos internacionales. La UNESCO ha formulado un cuerpo de recomendaciones para los diversos actores, en los cuales plantea claramente en sus sugerencias a los gobiernos la aprobación de marcos normativos que establezcan estándares de calidad y criterios compartidos de autorización y funcionamiento.

\section{Expansión de la cobertura}

Las estadísticas muestran claramente el aumento de la matrícula incentivado a su vez en la amplia diversidad de modalidades institucionales. A partir de la 
proyección de diversos estudios se puede asumir una hipótesis de crecimiento bajo que permitiría pensar la existencia de unos 984 mil estudiantes bajo modalidades híbridas que representarían el 6,4\% de la matrícula regional de América Latina para el año 2005, que permiten afirmar que la educación a distancia, o las modalidades despresenciales de la educación superior ya se han conformado como una nueva realidad importante del panorama de la educación superior en la región y cuyas tasas de incrementos son muy superiores a las tasas de expansión históricas de la educación tradicional presencial. Ello como derivación del desarrollo de un nuevo modelo socio-económico y tecnológico, así como de demandas de flexibilidad, mejores niveles de calidad de las ofertas, virtualización de la educación a distancia resultado de complejas reingenierías tecnológicas y organizacionales, mayores ofertas públicas por la eficacia de menores costos así como de proveedores internacionales, todo lo cual permite canalizar y facilitar estas demandas de amplios sectores de América Latina que buscan acceder a la educación como instrumento de mejoramiento de sus oportunidades.

La mayoría de los cursos aprobados son de licenciatura orientados a educación básica, existiendo también cursos diferenciados, como de graduación en salud indígena. Esta dinámica ha sido derivada de la experimentación de las instituciones a las cuales se les había permitido que hasta el 20\% de sus cursos fuera a distancia, así como de recursos públicos adicionales para incrementar esa oferta, y de una política de amplio licenciamiento de autorización a las instituciones para ofertar bajo las modalidad a distancia.

Mientras que en el 2002, la matricula presencial era de 3.030.754 la virtual era de 84.713 en 60 cursos (2,79\%), siendo la cobertura pública casi 99\%, para el 2007 se alcanzó a 339.00o alumnos universitarios en las distintas modalidades de educación a distancia siendo uno de los mayores actores de impulso a la creciente expansión terciaria de la cobertura en Brasil (Vianney, 2003). Como derivación Brasil se está consolidando como el país con la mayor matrícula de educación a distancia, que representa el $7 \%$ de la matrícula nacional.

\section{NOTAS}

1 Para poder comparar véase para Venezuela el caso de la Universidad Nacional Abierta a partir de su Plan Estratégico, Caracas, 2005 y para Colombia el Sistema Nacional de Información de la Educación Superior (SNIES) - Observatorio de la Universidad Colombiana, del 2008.

2 El Consorcio Clavijero busca capitalizar los niveles académicos de las IES participantes 
(públicas y privadas) para realizar ofertas de EV. Las instituciones participantes no pueden ofrecer cursos autónomamente a terceros y sus unidades se han dedicado a apoyar a sus alumnos presenciales. Tiene un ingreso de 350 alumnos en el $2005 \mathrm{y}$ 1200 en el 2006. La coordinación radica en la U. Veracruzana que tiene 5 campos conectados con 67 mil alumnos y una amplia red de telefonía IP. Los exámenes son presenciales en centros cercanos (incluido USA). El eje ha sido la enorme demanda de ingreso que tiene la U. Veracruzana ( $35 \mathrm{mil}$ ) y un cupo de 13 mil, o sea una relación de 3 a 1. Este es el mecanismo que han estructurado para resolver parte de la demanda insatisfecha.

3 En Argentina esta la situación del Campus Virtual de la Universidad Nacional de Rosario que para el 2007 contará con Sedes Regionales en funcionamiento en más de 40 sedes regionales distribuidas en distintos lugares del país, permitiendo acceder a los cursos y carreras desde las casas o desde las sedes regionales. En el marco de este proceso en todos los casos se han creado unidades académicas y administrativas diferenciadas dados los tradicionales bloqueos de gestión al interior de dichas instituciones, lo cual a su vez ha reforzado diversos desarrollos de e-learning.

4 La Open University está considerada una de las universidades británicas más prestigiosas. La mayoría de cursos de la OU están disponibles en Europa y algunos de ellos en el resto del mundo. Tiene cerca de 150.000 estudiantes universitarios entre los cuales, más de 30.000 son estudiantes de postgrado; unos 10.000 tienen discapacidades; la mayoría de los inscritos estudian a tiempo parcial; el 70\% tienen un trabajo de jornada completa; más de 50.000 están matriculados por su empresa; más de 25.000 viven fuera de la Gran Bretaña; tiene trece sedes en el país, una tercera parte han entrado con calificaciones más bajas que las solicitadas por otras universidades británicas. www.open.ac.uk

5 En el caso de la UNA un estudio realizado entre su matrícula de 80.184 alumnos en el 2004 correspondientes a sus 123 programas, indicaba que el 72\% no tienen PC con $\mathrm{CD}$, que sólo el 14\% tenía computadora personal en la oficina con CD, y que de la población que estudiaba, el 42,33\% procedía de los estratos más pobres IV y V de acuerdo con el método Graffer de estratificación. En ese contexto era consistente que la Universidad mostrara el menor índice de graduados de Venezuela. Gaceta Universitaria Universidad Nacional Abierta, No 48 extraordinario. "Plan Estratégico de la Universidad Nacional Abierta”, Caracas, 12-12-2005.

6 Véase al respecto los datos aportados por el Observatorio de la Educación Colombiana en http://www.universidad.edu.co/index.php?option=com_content\&task=view\&id $=35$ \&Itemid $=11$ (2 abril, 2009).

7 Para el caso de Cuba véase http://www.cubaportal.org/es/IC/ED/opcion_07.asp (2 abril 2009).

8 La Universidad Técnica Particular de Loja (UTPL) fue fundada por la Agrupación Marista Ecuatoriana (AME) el 3 de mayo de 1971 con autorización y apoyo de la Diócesis de Loja, y administrada por la misma hasta octubre de 1997. Actualmente la UTPL es regentada por la Asociación Id de Cristo Redentor, Misioneros y Misioneras Identes. Es una institución privada del interior del país que tiene 25 mil alumnos. Formación por videoconferencias con apoyo de tutores. Multiplicidad de subsedes de todo tipo en casi todas las ciudades (112) con tendencia a contener biblioteca y sala de videoconferencias. Tiene altas tasas de deserción, matrículas tendencialmente crecientes y una cobertura fuera del país con sedes en Estados Unidos, España e Italia 
orientadas a la población migrante ecuatoriana.

9 El proyecto de Estudios a Distancia de la Universidad Rafael Belloso Chacín (URBE) nace en 1999. Desde el inicio usa la plataforma WebCT. Se inició como una unidad para la oferta externa, pero desde el 2001 se convierte en una Unidad de Producción de Cursos a Distancia para todas las facultades en un proceso de vitualización de toda la Universidad en el área de educación continua, pregrado y postgrado. En 2005 se inauguró la nueva sede de Estudios a Distancia. Además de sus propios alumnos, la URBE ha suscrito convenios de asistencia con otras Universidades nacionales como la de Yacambú y UNEFA, así como con empresas.

10 La Universidad Blas Pascal es una institución privada con 9000 estudiantes y 60 sedes en todo el país desarrollados a través de Centros Facilitadores Tecnológicos (CFT) nacidos en convenios para brindar contención y soporte tecnológico a los alumnos dispersamente distribuidos en todo nuestro país, la UBP ha realizado alianzas con Instituciones privadas zonales, a las cuales se los denomina Centros Facilitadores Tecnológicos (CFT). Estos nodos conforman una red de educación a distancia denominada Comunidad Digital (http://www.comunidaddigital.net.ar). La función de Comunidad Digital es velar por que todos los CFT tengan la mejor calidad en el servicio ofrecido a los alumnos a distancia, ya que tanto el soporte tecnológico y estructural, como el asesoramiento y contención que se brinde en el centro, condiciona y mejora la calidad educativa del alumno. Además funciona para la recepción de exámenes, que sólo podrán ser administrados por profesores de la Universidad. En tanto la Blas Pascal es más virtual, la Universidad de Salta funciona bajo modalidades más hibridas. Las evaluaciones finales son presenciales.

11 Desde 1994 se desarrollo la UNAB Virtual con convenios de apoyo en postgrados con ITEM y UOC, y que promovió la Red Mutis, consorcio conformado por nueve instituciones universitarias privadas del interior, donde cada institución desarrolla sus propios modelos educativos para la modalidad virtual, a la par que se apropia de las posibilidades que le brindan la tecnología y la sinergia intra e interinstitucionales. En la UNAB el modelo tiende a presencial en pregrado con fuerte peso de TIC, y virtual en postgrados. Es miembro de la Red Mutis que han promovido el proceso de virtualización de algunas universidades privadas de Colombia en asociación con el Tec de Monterrey.

\section{REFERENCIAS BIBLIOGRÁFICAS}

Amador Bautista, R.(2007). La situación de la educación a distancia en México. VIII Encuentro Internacional Virtual Educa, Sao José Dos Campos.

Bates, A.W. (2001). Cómo gestionar el cambio tecnológico. Barcelona: Gedisa

Facundo, A. (2007). Por la calidad educativa y la equidad social. Foro Virtual Educa 2007, Sao José Dos Campos.

García Aretio, L. (coord) (2007). De la educación a distancia a la educación virtual. Barcelona: Ariel

García Aretio, L. (1999). Historia de la educación a distancia. RIED - Revista Iberoamericana de Educación a Distancia, Volumen 2, $\mathrm{N}^{\mathrm{o}}$ 1. I.S.S.N.: 1390 - 3306. [En línea] Disponible en: http://www.utpl.edu.ec/ried/index. php?option=com_content\&task=view\&i $\mathrm{d}=274 \&$ Itemid $=53$ [consulta 2009, $2 \mathrm{de}$ abril]

Llorens, V.(1995).Fundamentostecnológicos 
de vídeo y televisión. Barcelona: Paidos, Ministerio de Educación de Colombia. [En línea] Disponible en:

http://www.mineducacion.gov.co/1621/ article-85678.html [consulta 2009, 2 de abril]

Universidad Nacional Abierta (2005). Plan
Estratégico de la Universidad Nacional Abierta. Universitaria Universidad Nacional Abierta, $\mathrm{N}^{\circ} 48$ extraordinario. Caracas.

Vianney, J. (2007). La educación virtual en Brasil. Informe INEP. IESALC - Unisul, Florianopolis, 2003.

\section{PERFIL ACADÉMICO Y PROFESIONAL DEL AUTOR}

Claudio Rama Vitale. Investigador, profesor y consultor. Director del Observatorio de la Educación Virtual en América Latina de Virtual Educa. Ha sido Director del Instituto Internacional de la UNESCO para la Educación Superior en América Latina y el Caribe (IESALC) (2001-2006), Director del Instituto Nacional del Libro y Director del Sistema Nacional de Televisión del Uruguay. Ha realizado estudios que le han dado las certificaciones de Licenciado en Economía; Postgraduado en Derechos de Autor; Postgraduado en Propiedad Industrial; Especialista en Marketing; Especialista en Telemática y Educación a Distancia; Magíster en Gerencia Educativa; Doctor en Educación; Doctor en Derecho. www.claudiorama.name/ www. claudio-rama.blogspot.com /

E-mail: claudiorama@gmail.com

Fecha de recepción del artículo: 02/04/09

Fecha de aceptación del artículo: 06/11/09 